\title{
Regulation of natural killer cell function: a role for the NK cell's own MHC class I molecules
}

Received: 7 December 2004 / Published online: 20 January 2005

(C) Springer-Verlag 2005

Natural killer (NK) cells can attack cells infected with certain pathogens [1,2] and kill transformed cells [3]. Moreover, NK cells regulate adaptive immune responses [4]. Of clinical relevance is their ability to mediate in part the therapeutic activity of antibodies against tumors [5]. Finally, NK cells can influence the outcome of bone marrow transplantation. Recipient NK cells can completely prevent engraftment [6], whereas alloreactive donor NK cells can prevent graft versus host reactions [7] and may exert graft versus leukemia effects [7]. For a long time considered as being non-specific, the understanding of the molecular basis for the NK cell's discriminatory capacities has made considerable progress. We will distinguish three distinct recognition strategies used by NK cells to identify diseased or distressed host cells. These different recognition strategies do not act separately but are rather used in a cooperative fashion.

\section{Recognition of "non-self” ligands}

Natural killer cells detect pathogen-infected host cells by directly recognizing pathogen-encoded molecules. For instance, NK cells from certain mouse strains protect from lethal MCMV (Mouse Cytomegalovirus) infection. NK cells recognize the MCMV-encoded protein m157 on the surface of infected cells $[8,9]$. The recognition of this foreign protein is mediated by the $\mathrm{Ly} 49 \mathrm{H}$ receptor [10]. Interestingly, the NK-cell response selects MCMV variants with mutant $\mathrm{m} 157$, which escape $\mathrm{Ly} 49 \mathrm{H}$ recognition. If the early MCMV infection is counteracted by NK cells, mutant viruses are subsequently controlled

W. Held $(\bowtie) \cdot$ A. Chalifour $\cdot$ J. D. Coudert

Ludwig Institute for Cancer Research,

Lausanne Branch, University of Lausanne,

Ch. des Boveresses 155, 1066 Epalinges, Switzerland

E-mail: wheld@isrec.unil.ch

Tel.: +41-21-6925958

Fax: + 41-21-6534474 by an adaptive immune response [11]. These findings highlight the importance and the efficacy of NK cells during early MCMV infection. The human NKp46 and NKp44 NK-cell activation receptors may also be involved in pathogen recognition, as they were shown to bind influenza virus haemagglutinin [12].

In addition to recognizing pathogen-infected host cells, NK cells may have the capacity to directly recognize and respond to pathogen components through Tolllike receptors (TLRs) [13, 14].

\section{Recognition of constitutively expressed "self" ligands}

Besides the direct recognition of foreign protein or pathogen components, NK cells are equipped to determine whether various endogenous self-proteins are normally expressed. To this end, NK cells use a dual receptor system. They express a whole array of receptors that transmit activation signals upon interacting with a potential target cell [15]. In this context, we use the term "activation" to indicate the triggering of NK-cell effector functions such as cytolysis or the production of cytokines. In general, activation receptors are specific for incompletely defined, but constitutively expressed ligands on potential target cells. Under normal circumstances, NK-cell activation is counteracted by inhibitory NK-cell receptors, which interact with MHC-I (major histocompatibility complex class I) molecules on target cells. A significant number of inhibitory NK-cell receptors, which are specific for non-MHC-I ligands, have also been identified [16-19]. The importance of these receptors and how the signals from non-MHC and MHC-I-specific inhibitory receptors are integrated are currently unclear.

Natural killer cell inhibition by MHC-I on target cells enables NK cells to kill MHC-I loss variants. In this case, NK cells fail to receive inhibitory signals such that NK-cell activation can proceed unopposed. This type of recognition has been termed "missing-self" recognition [20]. Total or selective MHC-I loss or down-modulation 
is a frequent event during viral infections or transformation [21, 22]. It is thus thought that the recognition of MHC-I loss by NK cells complements T-cell-mediated immunity.

A special case of missing-self reactivity may be the lysis of immature dendritic cells (DC). NK-cell activation upon the interaction with DC occurs mainly via human NKp30. Mature DC are protected from lysis since they express high levels of HLA-E, which inhibits NK cells via the CD94/NKG2A receptor. In contrast, HLA-E expression on immature DC is low, allowing NK-cell-mediated lysis [23]. The interaction with DC likely reflects an immunoregulatory function of NK cells, which influences subsequent adaptive immune responses [24].

\section{Recognition of "induced-self" ligands}

In addition to activation receptors, which recognize constitutively expressed ligands, NK cells also express receptors, which are specific for ligands that can be induced on host cells but that are not normally expressed. The NKG2D receptor serves as a paradigm for this type of recognition (for review see [25]). Ligands for NKG2D, which include RAE, MULT1 and H60 proteins in the mouse and MICA/B and RAET in humans, are not normally expressed on host cells. Importantly, such ligands can be induced upon various cellular insults including stress [26], infection [27, 28] and transformation [29]. However, NKG2D ligands can also be induced during the course of normal cellular activation and differentiation [30]. Irrespectively, upon the interaction with host cells expressing NKG2D ligand, NK cells receive additional activation signals. In this case, host cells can be lysed even though they express MHC-I molecules normally, thus the term "induced-self" recognition [31]. Interestingly, the majority of the transformed cell lines commonly used in vitro constitutively express NKG2D ligands. An important area for future research will thus be to determine how these genes are regulated.

Besides NKG2D ligands, it has been noted before that CD80 (B7-1) expression by target cells can override NK-cell inhibition [32]. Moreover, antibody-dependent cell mediated cytotoxicity (ADCC) can be considered to belong to the same recognition category. NK cells can recognize and kill antibody-coated target cells, using Fc $\gamma$ RIII (CD16). Similar to NKG2D, ADCC can override NK-cell inhibition and allow the lysis of MHCI-expressing target cells [33].

Thus, over the last years, NK-cell activation has emerged as a complex and regulated process, which involves a significant number of distinct NK-cell receptors. Even though complete knowledge of all the relevant ligands is still lacking, it has become apparent that certain activation receptors recognize inducible ligands. Moreover, there are activating NK-cell receptors, such as human NKp44, that are themselves inducible via the action of cytokines [34].
In contrast to this, our view of NK-cell inhibition has remained relatively simple. NK-cell inhibition depended on the presence of the MHC-I ligand on the target cell and the presence of a specific inhibitory receptor on NK cells. We have recently made observations, which challenge this simplistic view. In order to discuss these findings and their implications, we will first introduce the experimental system we established over the past years.

\section{Inhibitory MHC-I receptors}

The prototype inhibitory receptor for classical MHC-I in mouse is Ly49A, a homodimeric C-type lectin-like receptor. Ly49A is part of a multigene family with $>20$ members $[35,36]$, whereby different mouse strains have variable numbers of $L y 49$ genes and individual receptors are polymorphic [37]. Ly49 receptors are tightly linked in the so-called NK gene complex (NKC) on mouse chromosome 6 [38].

Both inhibitory and activating Ly49 family members have been found. The function of the latter is still somewhat enigmatic, even though one activating Ly49, Ly49H, recognizes MCMV m157, as discussed above. The majority of the inhibitory receptors are specific for classical MHC-I [39]. Importantly, Ly49 receptors may be selective for certain MHC-I isotypes and may even discriminate certain alleles of MHC-I molecules. For instance, Ly49A inhibits mouse NK cells upon interaction with $\mathrm{H}-2 \mathrm{D}^{\mathrm{d}}\left(\mathrm{D}^{\mathrm{d}}\right)$ or $\mathrm{D}^{\mathrm{k}}$ but not $\mathrm{D}^{\mathrm{b}}$ or $\mathrm{H}-2 \mathrm{~K}$ on target cells [40].

The Ly49A receptor is expressed by approximately $20 \%$ of NK cells, irrespective of whether a particular mouse strain expresses a corresponding MHC-I ligand. This suggests that Ly49 receptor expression is not directed by MHC-I. Ly49 receptors are differentially expressed such that individual NK cells express a selection of the available receptors. Thus, using a relatively small number of receptors, NK cells generate a relatively complex receptor repertoire.

So far, functional Ly49 proteins have not been found in humans. Rather, human NK cells use a structurally distinct family of Ig-like receptors, the so-called killer inhibitory receptors (KIR) to recognize classical MHC-I molecules [41]. Despite the structural differences, KIR and Ly49 receptors mediate identical functions, are similarly selective for some but not all MHC-I molecules and are clonally distributed in a comparable fashion.

Cross-linking of inhibitory MHC-I receptors results in the phosphorylation of a tyrosine residue, which is central to the so-called ITIM (for immuno receptor tyrosine-based inhibition motif: I/S/T/LxYxxL/V), located in the cytoplasmic tail of the receptor. ITIM phosphorylation results in the recruitment and activation of phosphatases including SHP-1 and SHP-2 [42]. In turn, phosphatase activity interrupts the action of NK-cell activation pathways by dephosphorylating essential signaling intermediates, such as Vav1 [43]. 


\section{Ly49A transgenic mice}

In order to somewhat simplify the complex NK-cell receptor repertoire, we generated Ly49A transgenic $(\mathrm{Tg})$ mice [44]. In these mice, all NK cells have at least one inhibitory receptor in common. However, endogenous Ly49 receptors are still expressed [45]. The transgenic Ly49A conferred $\mathrm{D}^{\mathrm{d}}$-specific $\mathrm{NK}$-cell inhibition and prevented T-cell responses to allogeneic stimulator cells when these expressed inhibitory MHC-I ligand. This has provided formal evidence that Ly49A is an inhibitory receptor and not just a co-receptor for another, unknown receptor.

\section{NK-cell inhibition is regulated by the MHC-I of the NK cells}

Unexpectedly, the capacity of Ly49A to inhibit NK cells depends on the MHC-I background [46]. When NK cells are derived from a mouse strain lacking a Ly49A ligand such as $\mathrm{C} 57 \mathrm{BL} / 6(\mathrm{~B} 6)\left(\mathrm{H}-2^{\mathrm{b}}\right)$, Ly49A very efficiently inhibits the lysis of a $\mathrm{D}^{\mathrm{d}}$ transfected tumor target cell. In contrast, Ly49A NK cells from $\mathrm{D}^{\mathrm{d}}$ transgenic B6 mice were inefficient at inhibiting the lysis of these same targets, meaning that target cells were efficiently killed. Differential NK-cell inhibition was invoked since the lysis of the parental $\left(\mathrm{D}^{\mathrm{d}}\right.$-negative) tumor cells by the two NK-cell populations was identical. Thus, while NK-cell activation was near identical, NK-cell inhibition was very different.

While NK-cell inhibition via Ly49A was influenced by $\mathrm{D}^{\mathrm{d}}$ expression, the above experiments did not resolve whether $\mathrm{D}^{\mathrm{d}}$ was required in the environment or on the NK cells themselves. To address this issue, we used mice with mosaic expression of $\mathrm{D}^{\mathrm{d}}$ [47], in which $\mathrm{D}^{\mathrm{d}}$ expressing cells co-exist with those lacking $\mathrm{D}^{\mathrm{d}}$. NK cells from mosaic mice cannot kill target cells, which lack $\mathrm{D}^{\mathrm{d}}$, due to some poorly understood tolerance mechanism $[47,48]$. However, when the $\mathrm{D}^{\mathrm{d}}$-expressing NK cells are purified and cultured separately, they re-acquire the ability to kill $\mathrm{D}^{\mathrm{d}}$-negative targets [48]. Interestingly, Ly49A NK cells from mosaic mice, which expressed $\mathrm{D}^{\mathrm{d}}$, had a low capacity to inhibit NK-cell function. In contrast, those lacking $\mathrm{D}^{\mathrm{d}}$ had a high inhibitory capacity [46]. Since both types of NK cells developed in the same environment, it can be concluded that $\mathrm{D}^{\mathrm{d}}$ expression by the NK cells themselves determines Ly49A function.

\section{Reduced NK-cell inhibition correlates with reduced MHC-I binding}

Since Ly49A function was regulated by the NK cell's MHC-I, we tested whether this was related to the ability of Ly49A to bind MHC-I. To test this, we stained NK cells with soluble, multimeric, fluorochrome-labeled $\mathrm{D}^{\mathrm{k}}$, the alternative Ly49A ligand. The presence of $\mathrm{D}^{\mathrm{d}}$ on the NK cells reduced the binding of an anti-Ly49A mAb twofold. In contrast, $\mathrm{D}^{\mathrm{k}}$ multimer binding was $>10$-fold reduced. Thus, the capacity of Ly49A to bind soluble MHC-I ligand was significantly reduced when Ly49A was co-expressed with $\mathrm{D}^{\mathrm{d}}$.

Similar to B- or T-cell receptors, Ly49A can mediate the uptake of ligands from environmental cells. While the physiological relevance of this phenomenon for NK cells is uncertain, we used it to determine the capacity of Ly49A to interact with $\mathrm{D}^{\mathrm{d}}$ expressed on a target cell. Indeed, the NK cell's capacity to acquire $\mathrm{D}^{\mathrm{d}}$ via Ly49A was drastically reduced when Ly49A was co-expressed with $\mathrm{D}^{\mathrm{d}}$ [49]. Thus, Ly49A shows a limited capacity to bind MHC-I ligand on another cell when Ly49A is co-expressed with its MHC-I ligand on the same cell.

\section{Physical association of Ly49A and $D^{d}$ in cis}

Three independent lines of evidence showed that a large fraction of Ly49A receptors was physically associated with $\mathrm{D}^{\mathrm{d}}$ in the plane of the NK cell's membrane [46]. First, capping of Ly49A on living cells resulted in the cocapping of $\mathrm{D}^{\mathrm{d}}$ but not of CD45. This suggested that Ly49A and $\mathrm{D}^{\mathrm{d}}$ were indeed associated on living cells. Second, mild acid treatment was used to disrupt MHC-I complexes on the surface of living cells. The treatment of $\mathrm{D}^{\mathrm{d}}$-expressing NK cells with acid greatly improved the binding of MHC-I multimer to Ly49A. This suggested that Ly49A was masked by $\mathrm{D}^{\mathrm{d}}$ on the surface of NK cells. Finally, $\mathrm{D}^{\mathrm{d}}$ but not $\mathrm{D}^{\mathrm{b}}$ or $\mathrm{K}^{\mathrm{b}}$ co-immunoprecipitated with Ly49A. Thus, Ly49A and $\mathrm{D}^{\mathrm{d}}$ are physically associated in the plane of the NK cell's membrane. Interestingly, the interaction in cis and trans showed the same specificity for $\mathrm{D}^{\mathrm{d}}$. The association of Ly49A with $\mathrm{D}^{\mathrm{d}}$ in cis seems to mask the majority of Ly49A receptors such that they are unavailable to interact with MHC-I ligand in trans.

\section{The site of Ly49A-Dd interaction}

The crystal structure of Ly49A-D ${ }^{\mathrm{d}}$ complexes suggested the existence of two distinct sites of interaction between Ly49A and $\mathrm{D}^{\mathrm{d}}[50]$. On the one hand, Ly49A interacted with amino and carboxy terminal residues of the $\alpha 1$ and $\alpha 2$ helix, respectively (site 1 ). A second site was located laterally, beneath the floor of the peptide-binding groove, making contacts with residues of the $\alpha 2, \alpha 3$ and $\beta_{2} \mathrm{~m}$ domains (site 2). Interestingly, site 2 is similar to the binding site used by CD8 [51]. Subsequent site-directed mutagenesis analysis demonstrated that site 2 was the binding site used for Ly49A trans interaction, which mediates NK-cell inhibition [52, 53].

It was thus important to determine whether the binding site used for cis association was site 1 or site 2 or even an unknown third binding site. The analysis of a series of point mutations in $\mathrm{D}^{\mathrm{d}}$ as well as the use of species-specific differences in $\beta_{2} \mathrm{~m}$ revealed that $c i$ and 
trans interactions use the same binding sites, i.e. site 2 [46]. Thus, cis and trans interactions show exactly the same specificity.

Since binding site 2 is not symmetric, it is not immediately obvious how Ly49A can recognize $\mathrm{D}^{\mathrm{d}}$ in trans or cis using a single binding site. Moreover, a Ly49A homodimer interacts with a single $\mathrm{D}^{\mathrm{d}}$ molecule [50], suggesting that simultaneous binding in cis and trans is excluded. However, there is no structural information available regarding the Ly49A stalk (the connector between the plasma membrane and the carbohydrate recognition domain (CRD), which mediates MHC-I binding). We thus hypothesize that Ly49A adopts an extended conformation to recognize $\mathrm{D}^{\mathrm{d}}$ in trans, whereas a back-folded conformation would be required to interact with $\mathrm{D}^{\mathrm{d}}$ in cis. The above model implies that considerable flexibility of the Ly49A stalk is required to enable both cis and trans interactions by Ly49A. This model has some resemblance to the distinct conformational states adopted by active and resting integrins [54].

\section{Implications for NK-cell function}

Why should most of the Ly49A receptors be bound to $\mathrm{D}^{\mathrm{d}}$ in cis and thus be unavailable to inhibit NK-cell function upon the interaction with a $\mathrm{D}^{\mathrm{d}}$-expressing target cell? First, it is important to note that our functional evidence suggests that Ly49A, which is bound in cis, does not constitutively transmit inhibitory signals [46]. Thus, only the Ly49A receptors, which are available for trans interaction, seem to participate in NK-cell inhibition upon target cell interaction. Second, the small amount of accessible Ly49A on $\mathrm{D}^{\mathrm{d}}$-expressing NK cells is apparently sufficient to inhibit NK cells in response to normal, $\mathrm{D}^{\mathrm{d}}$-expressing target cells [55] and thus sufficient to ensure self-tolerance. Since the number of accessible Ly49A molecules is small, a relatively minor reduction in $\mathrm{D}^{\mathrm{d}}$ expression on target cells will be sufficient to abrogate NK-cell inhibition. Alternatively, minor increases in NK-cell activation, e.g. upon the expression of NKG2D ligands on target cells, are sufficient to overcome NK-cell inhibition [46].

\section{Concluding remarks}

Natural killer cell function is negatively regulated by inhibitory receptors interacting with MHC-I molecules expressed on target cells. We have found that the inhibitory Ly49A NK-cell receptor not only binds to its $\mathrm{D}^{\mathrm{d}}$ ligand expressed on potential target cells (i.e. in trans), but is constitutively associated with $\mathrm{D}^{\mathrm{d}}$ in cis (i.e. on the same cell). Cis association seems to limit the number of Ly49A receptors available for binding $\mathrm{D}^{\mathrm{d}}$ on target cells. In this way, cis association limits NK-cell inhibition via Ly49A. Consequently, cis association lowers the threshold at which NK-cell activation exceeds NK-cell inhibition. This allows an optimal discrimination of healthy from distressed or diseased host cells. Thus, the NK cell's own MHC-I plays an important role in the regulation of the function of murine NK cells.

Acknowledgements Research in this laboratory is supported in part by grants from the Swiss National Science Foundation (SNSF) and the Swiss Cancer League (Oncosuisse).

\section{References}

1. Biron CA, Nguyen KB, Pien GC, Cousens LP, Salazar-Mather TP (1999) Natural killer cells in antiviral defense: function and regulation by innate cytokines. Annu Rev Immunol 17:189-220

2. Scott P, Trinchieri G (1995) The role of natural killer cells in host-parasite interactions. Curr Opin Immunol 7:34-40

3. Kiessling R, Klein E, Wigzell H (1975) "Natural" killer cells in the mouse. I. Cytotoxic cells with specificity for mouse Moloney leukemia cells. Specificity and distribution according to genotype. Eur J Immunol 5:112-117

4. Raulet DH (2004) Interplay of natural killer cells and their receptors with the adaptive immune response. Nat Immunol 5:996-1002

5. Clynes RA, Towers TL, Presta LG, Ravtech JV (2000) Inhibitory $\mathrm{Fc}$ receptors modulate in vivo cytotoxicity against tumor targets. Nat Med 6:443-446

6. Cudkowicz G, Bennett M (1971) Peculiar immunobiology of bone marrow allografts. I. Graft rejection by irradiated responder mice. J Exp Med 134:83-102

7. Ruggeri L, Capanni M, Urbani E, Perruccio K, Shlomchik WD, Tosti A, Posati S, Rogaia D, Frassoni F, Aversa F, Martelli MF, Velardi A (2002) Effectiveness of donor natural killer cell alloreactivity in mismatched hematopoietic transplants. Science 295:2097-2100

8. Arase H, Mocarski ES, Campbell AE, Hill AB, Lanier LL (2002) Direct recognition of cytomegalovirus by activating and inhibitory NK cell receptors. Science 296:1323-1326

9. Smith HR, Heusel JW, Mehta IK, Kim S, Dorner BG, Naidenko OV, Iizuka K, Furukawa H, Beckman DL, Pingel JT, Scalzo AA, Fremont DH, Yokoyama WM (2002) Recognition of a virus-encoded ligand by a natural killer cell activation receptor. Proc Natl Acad Sci USA 99:88268831

10. Brown MG, Dokun AO, Heusel JW, Smith HRC, Beckman DL, Blattenberger EA, Dubbelde CE, Stone LR, Scalzo AA, Yokoyama WM (2001) Vital involvement of a natural killer cell activation receptor in resistance to viral infection. Science 292:934-937

11. French AR, Pingel JT, Wagner M, Bubic I, Yang L, Kim S, Koszinowski U, Jonjic S, Yokoyama WM (2004) Escape of mutant double-stranded DNA virus from innate immune control. Immunity 20:747-756

12. Mandelboim O, Liebermann N, Lev M, Paul L, Arnon TI, Bushkin Y, Davis DD, Strominger JL, Yewdell JW, Porgador A (2001) Recognition of haemagglutinins on virus infected cells by NKp46 activates lysis by human NK cells. Nature 409:10551060

13. Chalifour A, Jeannin P, Gauchat J-F, Blaecke A, Malissard M, N'Guyen T, Thieblemont N, Delneste Y (2004) Direct bacterial PAMP recognition by human NK cells involves TLRs and triggers a-defensin production. Blood 104:1778-1783

14. Sivori S, Falco M, Della Chiesa M, Carlomagno S, Vitale M, Moretta L, Moretta A (2004) CpG and double-stranded RNA trigger human NK cells by Toll-like receptors: Induction of cytokine release and cytotoxicity against tumors and dendritic cells. Proc Natl Acad Sci 101:10116-10121 
15. Colucci F, DiSanto JP, Leibson P (2002) Natural killer cell activation in mice and men: different triggers for similar weapons? Nat Immunol 3:807-813

16. Falco M, Biassoni R, Bottino C, Vitale M, Sivori S, Augugliaro R, Moretta L, Moretta A (1999) Identification and molecular cloning of p75/AIRM1, a novel member of the sialoadhesin family that functions as an inhibitory receptor in human Natural Killer cells. J Exp Med 190:793-801

17. Iizuka K, Naidenko OV, Plougastel BFM, Fremont DH, Yokoyama WM (2003) Genetically linked C-type lectin-related ligands for the NKRP1 family of natural killer cell receptors. Nat Immunol 4:801-807

18. Carlyle JR, Jamieson AM, Gasser S, Clingan CS, Arase H, Raulet DH (2004) Missing self-recognition of Ocil/Clr-b by inhibitory NKR-P1 natural killer cell receptors. Proc Natl Acad Sci USA 101:3527-3535

19. Lee K-M, McNerney ME, Stepp SE, Mathew PA, Schtzle JD, Bennett M, Kumar V (2004) 2B4 acts as a non-Major Histocompatibility complex binding inhibitory receptor on mouse Natural Killer cells. J Exp Med 199:1245-1254

20. Ljunggren HG, Kärre K (1990) In search of the 'missing self': MHC molecules and NK cell recognition. Immunol Today $11: 237-244$

21. Ploegh HL (1998) Viral strategies of immune evasion. Science 280:248-253

22. Ferrone S, Marincola FM (1995) Loss of HLA class I antigens by melanoma cells: molecular mechanisms, functional significance and clinical relevance. Immunol Today 16:487-494

23. Della Cheiasa M, Vitale M, Carlomagno S, Ferlazzo G, Moretta L, Moretta A (2003) The natural killercell-mediated killing of autologous dendritic cells is confined to a cell subset expressing CD94/NKG2A, but lacking inhibitory killer Ig-like receptors. Eur J Immunol 33:1657-1666

24. Martin-Fonteccha A, Thomsen LL, Brett S, Gerard C, Lipp M, Lanzavecchia A, Sallusto F (2004) Induced recruitment of NK cells to lymph nodes provides IFN-g for TH1 priming. Nat Immunol 5:1260-1265

25. Raulet DH (2003) Roles of the NKG2D immunoreceptor and its ligands. Nat Rev Immunol 3:781-790

26. Groh V, Bahram S, Bauer S, Herman A, Beauchamp M, Spies $\mathrm{T}$ (1996) Cell-stress regulated human major histocomaptibility complex class I gene expressed in gastrointestinal epithelium. Proc Natl Acad Sci USA 93:12445-12450

27. Groh V, Rhinehart R, Randolph-Habecker J, Topp MS, Riddel SR, Spies T (2000) Costimulation of CD8alphabeta T cells by NKG2D via engagement by MIC induced on virus-infected cells. Nat Immunol 2:255-260

28. Tieng V, Le Bouguenec C, du Merle L, Bertheau P, Desreumaux P, Janin A, Charron D, Toubert A (2002) Binding of Escherichia coli adhesin AfaE to CD55 triggers cell-surface expression of the MHC class I-related molecule MICA. Proc Natl Acad Sci 99:2977-2982

29. Girardi M, Oppenheim DE, Steele CR, Lewis JM, Glusac E, Filler R, Hobby P, Sutton B, Tigelaar RE, Hayday AC (2001) Regulation of cutaneous malignancy by gd T cells. Science 294:605-609

30. Diefenbach A, Jamieson AN, Liu S, Shastri N, Raulet DH (2000) Ligands for the murine NKG2D receptor: expression by tumor cells and activation of NK cells and macrophages. Nat Immunol 1:95-97

31. Diefenbach A, Raulet DH (2001) Strategies for target cell recognition by natural killer cells. Immunol Rev 181:170 184

32. Chambers BJ, Salcedo M, Ljunggren H-G (1996) Triggering of natural killer cells by the costimulatory molecule CD80 (B7-1). Immunity 5:311-317

33. Correa I, Corral L, Raulet DH (1994) Multiple natural killer cell-activating signals are inhibited by major histocompatibility complex class I expression in target cells. Eur J Immunol 24:1323-1331

34. Cantoni C, Bottino C, Vitale M, Pessino A, Auguliaro R, Malspina A, Parolini S, Moretta L, Moretta A, Biassoni R
(1999) NKp44, a triggering receptor involved in tumour cell lysis by activated human natural killer cells, is a novel member of the immunoglobulin superfamily. J Exp Med 189:787-795

35. Smith HRC, Karlhofer FM, Yokoyama WM (1994) Ly-49 multigene family expressed by IL-2-activated NK cells. J Immunol153:1068-1079

36. Anderson SK, Ortaldo JR, McVicar DW (2001) The everexpanding Ly49 gene family: repertoire and signaling. Immunol Rev 181:79-89

37. Held W, Roland J, Raulet DH (1995) Allelic exclusion of Ly49 family genes encoding class I-MHC-specific receptors on NK cells. Nature 376:355-358

38. Yokoyama WM, Seaman WE (1993) The Ly-49 and NKRP1 gene families encoding lectin-like receptors on natural killer cells: the NK gene complex. Annu Rev Immunol 11:613-635

39. Hanke T, Takizawa H, McMahon CW, Busch DH, Pamer EG, Miller JD, Altman JD, Liu Y, Cado D, Lemonnier FA, Bjorkman PJ, Raulet DH (1999) Direct assessment of MHC class I binding by seven Ly49 inhibitory NK cell receptors. Immunity 11:67-77

40. Karlhofer FM, Ribaudo RK, Yokoyama WM (1992) MHC class I alloantigen specificity of Ly-49+ IL-2 activated natural killer cells. Nature 358:66-70

41. Colonna M, Samaridis J (1995) Cloning of immunoglobulinsuperfamily members associated with HLA-C and HLA-B recognition by human natural killer cells. Science 268:405408

42. Burshtyn D, Scharenberg A, Wagtmann N, Rajagopalan S, Peruzzi M, Kinet J-P, Long EO (1996) Recruitment of tyrosine phosphatase HCP by the NK cell inhibitory receptor. Immunity $4: 77-85$

43. Stebbins CC, Watzl C, Billadeau DD, Leibson PJ, Burshtyn DN, Long EO (2003) Vav1 dephosphorylation by the tyrosine phosphatase SHP-1 as a mechanism for inhibition of cellular cytotoxicity. Mol Cell Biol 23:6291-6299

44. Held W, Cado D, Raulet DH (1996) Transgenic expression of the Ly49A natural killer cell receptor confers class I Major Histocompatibility Complex (MHC)-specific inhibition and prevents bone marrow allograft rejection. J Exp Med 184:20372041

45. Held W, Dorfman JR, Wu M-F, Raulet DH (1996) Major histocompatibility complex class I dependent skewing of the natural killer cell Ly49 receptor repertoire. Eur J Immunol 26:2286-2292

46. Doucey MA, Scarpellino L, Zimmer J, Guillaume P, Luescher IF, Bron C, Held W (2004) Cis-association of Ly49A with MHC class I restricts natural killer cell inhibition. Nat Immunol 5:328-336

47. Ioannidis V, Zimmer J, Beermann F, Held W (2001) Cre recombinase-mediated inactivation of $\mathrm{H}-2 \mathrm{Dd}$ transgene expression: evidence for partial missing-self recognition by Ly49A NK cells. J Immunol 167:6256-6262

48. Johansson $\mathrm{MH}$, Bieberich $\mathrm{C}$, Jay $\mathrm{G}$, Kärre $\mathrm{K}$, Höglund $\mathrm{P}$ (1997) Natural killer cell tolerance in mice with mosaic expression of major histocompatibility complex class I molecules. J Exp Med 186:353-364

49. Zimmer J, Ioannidis V, Held W (2001) H-2D ligand expression by Ly49A + Natural Killer (NK) cells precludes ligand uptake from environmental cells: implications for NK cell function. J Exp Med 194:1531-1539

50. Tormo J, Natarajan K, Margulies DH, Mariuzza RA (1999) Crystal structure of a lectin-like natural killer cell receptor bound to its MHC class I ligand. Nature 402:623-631

51. Kern PS, Teng M, Smolyar A, Liu J, Liu J, Hussey RE, Spoerl R, Chang H-C, Wang J (1998) Structural basis of CD8 corecptor function revealed by crystallographic analysis of a murine CD8aa ectodomain fragment in complex with $\mathrm{H}-2 \mathrm{~Kb}$. Immunity 9:519-530

52. Matsumoto N, Mitsuki M, Tajima K, Yokoyama WM, Yamamoto K (2001) The functional binding site for the C-type lectin-like natural killer cell receptor Ly49A spans three 
domains of its Major Histocompatibility Complex class I 54. Shimaoka M, Springer TA (2003) Therapeutic antagonists and ligand. J Exp Med 193:147-157

53. Wang J, Whitman MC, Natarajan K, Tormo J, Mariuzza RA, conformational regulation of integrin function. Nat Rev Drug Discov 2:703-716

Margulies DH (2002) Binding of the Natural Killer cell inhibitory receptor Ly49A to its Major Histocompatibility Complex class I ligand. J Biol Chem 277:1433-1442

55. Dorfman JR, Raulet DH (1996) Major histocompatibility complex genes determine natural killer cell tolerance. Eur J Immunol 26:151-155 